\title{
Implications of the transition from shield to rejuvenation in Samoa
}

\author{
J. G KONTER ${ }^{1}$, M.G. JACKSON ${ }^{2}$, A.A.P. KOPPERS ${ }^{3}$
}

${ }^{1}$ U. of Hawaii, Manoa, Honolulu, HI 96822

${ }^{2}$ U. California Santa Barbara, Santa Barbara, CA 93106

${ }^{3}$ Oregon State U., Corvallis, OR 97331

The geochemical composition of hotspot volcanoes changes throughout their constructional history, reflecting both changes in magmatic processes and mantle sources. In the type example of Hawaii, this involves an evolution through pre-shield, shield, post-shield and rejuvenated stages that sample multiple mantle components, while the derived magmas evolve at different depths within the volcanic structures. The overall pattern reflects an interplay between sampling across the plume conduit, and maximum magma generation over the center of the conduit. The transition from the shield to post-shield features a welldocumented change to more alkalic, lower degree melts with decreasing volumes of erupted melts, and a concurrent deepening of the main magma chamber, all related to the shift to the cooler plume periphery [1]. After a variable timespan of magmatic quiescence, this is followed by a rejuvenated stage, which may originate from a component of pyroxenite melting coupled to small-scale convection [2].

In the case of Samoa, a Tutuila drill core [3] shows a temporal evolution for Samoan mantle components; an EM2 shield is followed by a more isotopically depleted postshield. After a $\sim 1$ Myr pause in volcanic activity, rejuvenation features an EM1-type compositions. $\mathrm{Sr}-\mathrm{Nd}-\mathrm{Pb}$ isotopes and the presence of trachyte suggests a similar post-shield on Savaii. ${ }^{40} \mathrm{Ar} /{ }^{39} \mathrm{Ar}$ ages show this occurred between $\sim 2-0.9 \mathrm{Ma}$, extending total duration of shield and post-shield volcanism in Savaii to $\sim 4 \mathrm{Myr}$, followed by rejuvenation with no pause in activity. This contrasts with Hawaii, where total shield and post-shield volcanism may span $2 \mathrm{Myr}$, followed by a 0.5-2.5 Myr gap in activity. One explanation simply relates this duration to the time the volcano is situated over the plume conduit. Given similar plate motion for Hawaii and Samoa, this would require a (2x) wider conduit in Samoa. Instead, small scale convective modification of the plume upwelling, combined with pyroxenite melting can extend shield and post-shield activity [4], leading to overlap with rejuvenation activated by flexural melting of metasomatized mantle veins [5].

[1] Sinton (2017) JVGR 340 30-51 [2] Garcia (2016) 185 278-301 [3] Reinhard (2019) $\mathrm{G}^{3}$ 10.1029/2018GC00 7985 [4] Ballmer (2013) EPSL 376 155-164 [5] Konter (2012) $\mathrm{G}^{3}$ 10.1029/2011GC003974 